2019

Debating the geographies of contemporary higher education students: diversity, resilience, resistance?

\author{
Holton, Mark
}

http://hdl.handle.net/10026.1/12766

10.1080/14733285.2018.1536777

Children's Geographies

Taylor \& Francis (Routledge)

All content in PEARL is protected by copyright law. Author manuscripts are made available in accordance with publisher policies. Please cite only the published version using the details provided on the item record or document. In the absence of an open licence (e.g. Creative Commons), permissions for further reuse of content should be sought from the publisher or author. 


\section{Debating the geographies of contemporary higher education students: diversity, resilience, resistance?}

Holton, Mark (2018) - School of Geography, Earth, and Environmental Sciences, University of Plymouth

Accepted - 09 Oct 2018 (embargo until 09 Oct 2019)

Cite this article: Holton, M. (2018). Debating the geographies of contemporary higher education students: diversity, resilience, resistance? Children's Geographies, DOI: 10.1080/14733285.2018.1536777

\section{Abstract}

Nearly twenty years have passed since the publication of Cool Places: Geographies of Youth Cultures and the debates surrounding belonging, identity, resistance and marginalisation raised by Skelton and Valentine have become ever more vital. As a result, youth Geographers have been fundamental in pushing the boundaries of research in these areas. Through this paper, I argue for more critical reconsideration of how such debates can be enlivened further through investigation into the geographies of higher education students. In doing so, I elucidate upon how we might more effectively examine notions of post-adolescent mobilities and experiences.

\section{Keywords}

Geography, higher education, students, youth, resilience, resistance

\section{Introduction}

Research into the geographies of children and young people has gained considerable momentum over the last twenty years since Tracey Skelton and Gill 
Valentine published their edited collection Cool Places: Geographies of Youth Cultures in 1998. This text brought an emerging set of vital debates featuring the voices of young people to the fore, paving the way for youth studies to become a key component of geographical enquiry. Through their book, Skelton and Valentine brought the everyday lives (and struggles) of a global youth population on the cusp of a new millennium into sharper focus through a set of critical investigations that recognised 'youth' as a new lens through which to examine notions of belonging, identity, resistance and marginalisation. Using Cool Places as a benchmark for contemporary youthful debates, I take this opportunity to reflect upon some of the challenges faced by Geographers in researching $21^{\text {st }}$ Century youth. I focus on the post-adolescent stage of the life-course to argue that the geographies of higher education (HE) students provide stimulating new directions for youth-oriented research that stretch beyond the binaries of (in)equality and (im)mobility and engage more effectively with wider understandings of youth and young people. I contend that contemporary youth has become increasingly fractured into oppositional generational shifts and protracted through financial burdens that encumber, rather than support youthfulness. To comprehend this, I take two dimensions gleaned from Skelton and Valentine's book - matters of scale and place, and notions of youthful sites of/for resistance - and give them an HE 'twist' to demonstrate how youth Geographers can respond to the contemporary societal pressures placed upon young HE students in the $21^{\text {st }}$ Century.

\section{Matters of scale and place}

Cool Places opens with a call to recognise the diversity of young people as a way of demystifying the homogeneity of 'youth' (Valentine et al., 1998). Contemporary 
theorising in student geographies has followed in this vein, focusing on the intersections between class, belonging and identity to illuminate the socio-spatial inequalities faced by young students in accessing and interpreting HE. Yet these often relational understandings of studenthood - traditional vs. non-traditional, local vs. non-local, mobile vs. immobile - have made notions of scale and institutional fit persistent and problematic in terms of who should (not) fit in whilst at university. This has been observed through the interplay of policies and public discourses around authenticity, independence and transition and highlights the competing forms of classification that have become attached to particular experiences of student (im)mobility and belonging. Notably, current thinking has begun to 're-imagine' the student experience in new and exciting ways. For example, adopting postBourdieusian approaches, Donnelly and Evans (2016) and Finn (2017) have problematised the aforementioned rigid binaries that are (re)produced through Bourdieu's concepts of habitus, capital and field. These debates are crucial for advancing scholarly understanding of how young people approach, interpret and manage $\mathrm{HE}$, by questioning the social reproduction of classed, cultural, gendered and aged identities. These approaches suggest that while young people may be steered towards educational choices that are assumed to best prepare them for adult life, their backgrounds, identities and aspirations may produce various levels of uncertainty that subsequently impact upon their lived futures.

It is important to remember though that beyond the academy, knowledge of youthfulness has real-world consequences and media scrutiny of youth transitions into global HE networks has accentuated the implications of 'siloing' young people that perpetuate inequalities. This is particularly noticeable in terms of mental health and perceptions of 'resilience', and the consequential (and perhaps even inevitable) 
production of confusion, isolation and constraint among young people. According to a recent YouGov (2016) study, one-in-four UK HE students have reported a mental health issue, with 77 per cent reporting depression-related problems and 74 per cent declaring anxiety related issues. These statistics are, of course, worrying yet youth Geographers are well equipped to contribute to these debates through the intersecting theorisations of scale, place and mobility. Research on student mobilities, for example, interrogates the intersections of students' everyday lives and I draw here on notable work that recognises young people's manifold identities and that follows in the footsteps of the pioneering conceptual work situated in Cool Places. Exploring the power dimensions experienced by international students, Ploner (2016) challenges narrow classification regimes and calls for a critical reevaluation of the relationship between international student mobilities and other contemporary forms of migration, displacement and diaspora. In terms of identity, Robertson's (2016) study of trans-local student friendships examines the subjectivities that shape senses of self among migrant students living in Melbourne, Australia, and how these are multiply located and negotiated. Collins' (2010) work on South Korean students residing in New Zealand explores the friction involved when interpreting familiar and unfamiliar embodied experiences whilst temporarily residing in term-time spaces, and the implications for place-making. Finally, Holton and Finn (2018) explore practices of mobility for living-at-home students in the UK to examine the senses of belonging and the emotional reflections that are afforded by performances associated with being a commuter student. Crucially, these debates take cues from Barker et al. (2009) to examine the intersections that exist between different scales of mobilities, places and ages, and how these affect, enable, and 
potentially disadvantage young students' feelings of, and strategies for, coping with the pitfalls of student life.

\section{Youthful sites of (and for) resistance}

So, where do we go from here? Cool Places was published at a time of global political change - with 'Cool Britannia' situating the UK in particular as, quite literally, the 'coolest' place in the world! Yet twenty years on, global HE networks are in a state of flux. With ongoing political instability in the UK since the vote for Brexit, and the fall-out from Donald Trump's Muslim travel ban in America, issues of student experiences, identities and mobilities are placed firmly on the table. From debates about who has the right to travel to (and remain within) countries for HE and how such mobilities should be categorised, to the increasingly politicised discourses surrounding the material and symbolic costs of study, belonging and citizenship, there is renewed academic focus on the uneven and inequitable access to the practices and movements associated with global HE networks.

In Cool Places, young people are characterised as relational to, or as burdening, the regulatory regimes of the state and within $\mathrm{HE}$ research this is witnessed through a resurgence of the university as a site for resistance. Media coverage of an increasing global politicisation of HE students has emphasised the importance and timeliness of exploring the motivations for young people to become involved in political action and how such action is intrinsically linked to the geographies of youth, students and global HE reform. Contemporary academic work has sought to challenge and destigmatise young people as apolitical, instead representing young students as informed political actors. Examples of this have focused upon protests over tuition fee increases in the UK in 2010 (Hopkins et al., 2012) and South Africa in 2016 
(Webb, 2018); and the student-led pro-democracy protests in Hong Kong in 2014-15 (MacFarlane, 2016) and in Chile in 2011 and 2014 (Guzman-Valenzuela, 2016). In the media, this has included the perceived role of UK students in galvanising support for the Labour Party's 2017 General Election campaign as well as the mobilisation of the alt-right in the US which resulted in the tragedies in Charlottesville, Virginia in 2017. Craig Jeffrey (2010) questions the role of children and young people as 'alchemists of the revolution', and among these authors' research, this message certainly rings true, with contemporary young students appearing to swap perceived hedonistic, entitled and unencumbered identities to become more informed, motivated and responsible citizens, albeit in somewhat particularlist, non-local and informal ways. It can be argued then that student activism is becoming increasingly motivated through endemic fears based around precarity through the loss of aspiration, job security and social mobility. This has spurred a renaissance in student radicalism, particularly in terms of how campuses have once again become sites for organised resistance among young people. Yet while Pusey and Sealey-Huggins (2013) cleave such student movements apart, arguing that differences exist between reactive action and action motivated to stimulate meaningful change, they acknowledge that such differences "form part of the messy and contingent process of taking part in political action and social movement struggles" (p.453).

\section{Conclusion}

To return to the compelling dimensions of relationality, resistance and representation that Skelton and Valentine (1998) promoted in Cool Places, we can view comparable issues even more starkly through a $21^{\text {st }}$ Century lens. Here though, notions of scale, place and resistance are perceived as somewhat paradoxical, with young students 
adopting identities that might situate them as at once vulnerable and active citizens; of needing protection, whilst simultaneously resisting the stereotypes placed upon them. Hence, future work can usefully consider contemporary student experiences in terms of place-making, diversity and difference to make important, meaningful contributions to wider disciplinary knowledges of social change and reproduction. I argue then that it is essential for this work to explore the performances that coproduce HE experiences in ways that attend specifically to how place and mobility have become intrinsically entwined for young people, and in what manner this is performed through a constant (re)negotiation of movement and sense of place that contributes towards the diversity of unconventional student lives.

\section{References}

Barker, J., P. Kraftl, J. Horton and F. Tucker, 2009. "The road less travelled-new directions in children's and young people's mobility." Mobilities 4(1): 1-10.

Collins, F.L, 2010. "Negotiating un/familiar embodiments: Investigating the corporeal dimensions of South Korean international student mobilities in Auckland, New Zealand." Population, Space and Place, 16(1): 51-62.

Donnelly, M., and C. Evans, 2016. "Framing the geographies of higher education participation: Schools, place and national identity." British Educational Research Journal, 42(1): 74-92.

Finn, K, 2017. "Multiple, relational and emotional mobilities: Understanding student mobilities in higher education as more than 'staying local' and 'going away'." British Educational Research Journal, 43(4): 743-758. 
Guzmán-Valenzuela, C, 2016. "Neoliberal discourses and the emergence of an agentic field: The Chilean student movement." In Student politics and protest, international perspectives edited by R. Brooks, 47-62. London: Routledge/SRHE.

Holton, M., and K. Finn, 2018. "Being-in-motion: The everyday (gendered and classed) embodied mobilities for UK university students who commute." Mobilities, 13(3): 426-440.

Hopkins, P., L. Todd, and Newcastle Occupation, 2012. "Occupying Newcastle University: student resistance to government spending cuts in England." The Geographical Journal, 178(2): 104-109.

Jeffrey, C, 2013. "Geographies of children and youth III: Alchemists of the revolution?." Progress in Human Geography, 37(1), 145-152.

MacFarlane, B, 2016. 'If not now, then when? If not us, who?': understanding the student protest movement in Hong Kong." In Student politics and protest: international perspectives edited by R. Brooks, 143-156. London: Routledge/SRHE.

Ploner, J, 2017. "Resilience, moorings and international student mobilities-Exploring biographical narratives of social science students in the UK." Mobilities, 12(3), 425444.

Pusey, A., and L. Sealey-Huggins, 2013. "Transforming the university: Beyond students and cuts." ACME, 12(3), 443-458.

Robertson, S, 2016. "Friendship networks and encounters in student-migrants' negotiations of translocal subjectivity." Urban Studies, 55(3), 538-553. 
Skelton, T., and G. Valentine, (Eds.) 1998. "Cool places: Geographies of youth cultures." London: Routledge.

Valentine, G., T. Skelton, and D. Chambers, 1998. "Introduction." In Cool places:

Geographies of youth cultures edited by T. Skelton and G. Valentine, 1-34. London: Routledge.

Webb, C, 2018. "Asinamali: aspiration, debt and citizenship in South Africa's \#FeesMustFall protests." Area, doi.org/10.1111/area.12489.

YouGov, 2016. "One in four students suffer from mental health problems." https://yougov.co.uk/news/2016/08/09/quarter-britains-students-are-afflicted-mentalhea/ 